\title{
Comparison of High Strength Steels with Different Aluminium and Manganese Contents Using Dilatometry
}

Jan Hajsman, Ludmila Kucerova, Karolina Burdova

Regional Institute of Technology, Faculty of Mechanical Engineering, University of West Bohemia. Univerzitni 8, 30614 Plzen. Czech Republic. E-mail: janh@rti.zcu.cz, skal@rti.zcu.cz

In this paper, the properties of three low carbon steels containing different percentage of manganese (1.5 or $3 \mathrm{wt} \%)$ and aluminium ( $1.5 \mathrm{or} 2 \mathrm{wt} \%)$ were tested using dilatometric analysis and metallography. The steels had chemical compositions typical for TRIP (Transformation induced plasticity) steels and the two steels with an increased manganese content already belonged to the third generation of AHS (advanced high strength) steels. The dilatometric measurement was employed not only to determine the characteristic transformation temperatures but also to simulate the heat treatment procedure commonly used for TRIP steels. Resulting microstructures obtained through this simulation were evaluated and compared. The two main alloying elements were proved to have a significant effect on the transition temperatures and thus on the processability and overall resulting properties of the material.

Keywords: Dilatometric Analysis, TRIP steel, Bainitic Steel, CCT Diagram, Transformation Temperature

\section{Introduction}

The automotive industry is the main driving force in the search for new grades of steels which feature all the desirable properties like high strength, significant total elongation and low weight and at once. The main focus is currently put on TRIP steels (transformation induced plasticity) containing retained austenite in their microstructure which can transform to martensite during cold plastic deformation. This phenomenon contributes to the increase of homogenous deformation and thus increase in strength and total elongation $[1,2]$. The so-called third generation of advanced high strength steels tends to combine the exceptional mechanical properties of previous generations with relatively low costs [3, 4]. An important group of the third generation are medium manganese steels containing 3-12\% Mn. Medium manganese steel is usually processed with hot rolling, cold rolling, and intercritical annealing, where the strain-induced martensite reverse transformation was proposed to enhance the yield and ultimate tensile strength. The ultimate tensile strength values were reported in a range from 800 to $1400 \mathrm{MPa}$ with total elongation from 20 to $40 \%[5,6]$. The decrease of weight is usually achieved by adding a light alloying element such as aluminum which also contributes to higher specific strength [7]. Aluminum also appears to be a sufficient substitute for silicon as an alloying element in terms of solid solution strengthening and suppression of carbide formation [2]. Moreover, the replacement of silicon by aluminum solves the problem of surface quality deteriorating caused by the formation of silicon oxides [2]. Besides the chemical composition, appropriate heat treatment is crucial for the formation of the desired microstructure. The procedure typically used for TRIP steels include austenitization, then cooling down and hold in the region of bainite transformation. The duration of this hold is designed to ensure the development of a suitable proportion of bainite and for sufficient carbon enrichment of retained austenite [6].

This work aimed to examine the influence of slightly increased manganese and aluminum weight percentage $(3 \%$ and $1.5 \%$ or $2 \%$ respectively) on transformation temperatures and microstructure of TRIP steels by the means of dilatometric analysis. These two experimental materials were compared with typical TRIP steel containing $1.5 \mathrm{wt} \%$ of manganese and $1.5 \mathrm{wt} \%$ of aluminum. The dilatometric analysis evaluates the changes in a sample length during defined heat treatment [8]. These changes correspond to phase transformations, which are typically accompanied by dimension changes of the sample caused by the re-arrangement of the atoms during phase transition. In this way, critical temperatures of the steel, such as Ac1, Ac3 martensite start (Ms) and martensite finish (Mf) temperatures can be determined and even the transformation rate can be established [9]. The knowledge of these temperatures, together with the choice of the suitable cooling rate are necessary factors for the successful design of heat treatment of steels [10-14]. Therefore, dilatometry is an important tool for the study of multiphase high strength steels and their heat and thermo-mechanical treatment. However, to obtain unambiguous results, the dilatometry needs to be supported by metallographic analysis. Especially for high strength steels it is necessary to dis- 
tinguish between martensitic and bainitic transformation, to monitor the volume fraction of all microstructural constituents etc.[?].

\section{Experimental program}

The experimental program was focused on three low carbon steels (Table 1.) which significantly differ only in manganese and aluminum content. The first two materials represent the main object of the study, whereas the third $(1.5 \mathrm{Al}-1.5 \mathrm{Mn})$ was used as a reference. For the assessment of the overall impact of the alloying elements, the $\mathrm{Mn} / \mathrm{Al}$ ratio was used. Despite it was partially replaced with aluminum, a certain amount of silicon $(0.6 \mathrm{wt} \%)$ was added to improve solid solution strengthening. Furthermore, the addition of a very low percentage of niobium $(0.06 \mathrm{wt} \%)$ ensures postponing of pearlite transformation and thus enables the use of relatively slow cooling rates [6], [14]. The JMatPro software was used to calculate CCT (continuous cooling transformation) diagrams of all three experimental steels.

$50 \mathrm{~kg}$ ingots of experimental steels were vacuum cast, cut into four equal parts and forged into bars using laboratory hydraulic press. The forging of the steels was carried out with one-hour soaking at the temperature of $1150^{\circ} \mathrm{C}$ for $2 \mathrm{Al}-3 \mathrm{Mn}$ and $1.5 \mathrm{Al}-1.5 \mathrm{Mn}$ steels and one hour soaking at the temperature of $1050^{\circ} \mathrm{C}$ for $1.5 \mathrm{Al}-3 \mathrm{Mn}$ steel. Forged bars were further annealed for two hours at $950^{\circ} \mathrm{C}$ in laboratory furnace and air-cooled to room temperature. Cylindrical samples with $5 \mathrm{~mm}$ diameter and $10 \mathrm{~mm}$ height were prepared from the bars for dilatometric analysis.

Tab. 1 Chemical composition of experimental materials, wt $\%$

\begin{tabular}{cccccccccc}
\hline & $\mathbf{C}$ & $\mathbf{S i}$ & $\mathbf{M n}$ & $\mathbf{P}$ & $\mathbf{S}$ & $\mathbf{C r}$ & $\mathbf{A l}$ & $\mathbf{N b}$ & $\begin{array}{c}\text { Mn/Al } \\
\text { ratio }\end{array}$ \\
\hline $1.5 \mathrm{Al}-3 \mathrm{Mn}$ & 0.2 & 0.6 & 3.0 & 0.008 & 0.003 & 0.19 & 1.5 & 0.06 & 2 \\
$2 \mathrm{Al}-3 \mathrm{Mn}$ & 0.2 & 0.6 & 3.0 & 0.008 & 0.003 & 0.17 & 2.0 & 0.06 & 1.5 \\
$1.5 \mathrm{Al}-1.5 \mathrm{Mn}$ & 0.2 & 0.6 & 1.5 & 0.008 & 0.003 & 0.19 & 1.5 & 0.06 & 1
\end{tabular}

Samples were subjected to four different procedures of dilatometric analysis, using the L75PT instrument. The first procedure was designed to determine the Ac1 and the Ac3 temperature. First, the sample was heated up to $600{ }^{\circ} \mathrm{C}$ with a heating rate 10 ${ }^{\circ} \mathrm{C} / \mathrm{min}$, then the heating rate was decreased to 3 ${ }^{\circ} \mathrm{C} / \mathrm{min}$ and the heating continued to $1100{ }^{\circ} \mathrm{C}$. For confirmation, this measurement was performed twice.

To determine the temperatures of martensite and bainite formation, two slightly different procedures were carried out. In both cases, the sample was heated up to $1000{ }^{\circ} \mathrm{C}$ with decreasing heating rate $\left(5^{\circ} \mathrm{C} / \mathrm{s}\right.$ to $500{ }^{\circ} \mathrm{C}, 2^{\circ} \mathrm{C} / \mathrm{s}$ to $900{ }^{\circ} \mathrm{C}, 1^{\circ} \mathrm{C} / \mathrm{s}$ to $1000{ }^{\circ} \mathrm{C}$ ). Then the samples were cooled down with two different cooling rates, i.e. $50{ }^{\circ} \mathrm{C} / \mathrm{s}$ and $14{ }^{\circ} \mathrm{C} / \mathrm{s}$. These are the expected minimal and maximal cooling rates applicable to the processing of these particular experimental steels, which could be industry-relevant. The fourth dilatometric procedure was designed to simulate a heat treatment commonly used for TRIP steels. The sample was heated up in the same manner as in the previous case, then it was cooled down to $425{ }^{\circ} \mathrm{C}$ at 14 ${ }^{\circ} \mathrm{C} / \mathrm{min}$. Then a 30 minute hold followed to enable the bainite formation. Finally, the sample was cooled down to room temperature at $3{ }^{\circ} \mathrm{C} / \mathrm{min}$. Two-step heat treatment of this type is typically used for processing of TRIP steels and these particular parameters of heat treatment were chosen based on previous experiments with steels of similar composition [4], [11]. The resulting microstructures were analysed with SEM and light microscopy.

For all three steels CCT diagrams and equilibrium transformation temperatures were calculated in
JMatPro software to analyse the alloying elements' effect and to compare calculated data with experimental ones.

\section{Results and discussion}

\subsection{Calculated CCT diagram}

The JMatPro calculated CCT diagram (Fig. 1) shows the effect of varying aluminum and manganese content. From a comparison of the steels containing an identical percentage of aluminum can be concluded that the increase of manganese content from $1.5 \mathrm{wt} \%$ to $3 \mathrm{wt} \%$ has a significant impact on transformation temperatures. All of the transformation regions were shifted to longer times and lower temperatures. The most distinctive shift is apparent from the comparison of the ferrite-start curves (Fig.1), transformation temperatures Ac1 and Ac3 and martensite formation temperatures (Tab. 2). The effect of the change of aluminum content can be demonstrated on the example of $1.5 \mathrm{Al}-3 \mathrm{Mn}$ an $2 \mathrm{Al}-3 \mathrm{Mn}$ steels. The increase in aluminum content by $0.5 \mathrm{wt} \%$ shortened the austenite to ferrite transformation incubation time and shifted the transformation region to higher temperatures. Also, the martensite formation temperatures increased with aluminum content, whereas the pearlite-start and bainite-start curves didn't show any significant change.

To describe the simultaneous effect of the alloying elements it appears to be convenient to take into account the manganese/aluminum ratio. Above all, it can be concluded that with the increasing $\mathrm{Mn} / \mathrm{Al}$ ratio the austenite to ferrite transformation incubation time is increasing and the corresponding curve is shifted to 
lower temperatures. A similar conclusion can be applied for all of the transformation curves.

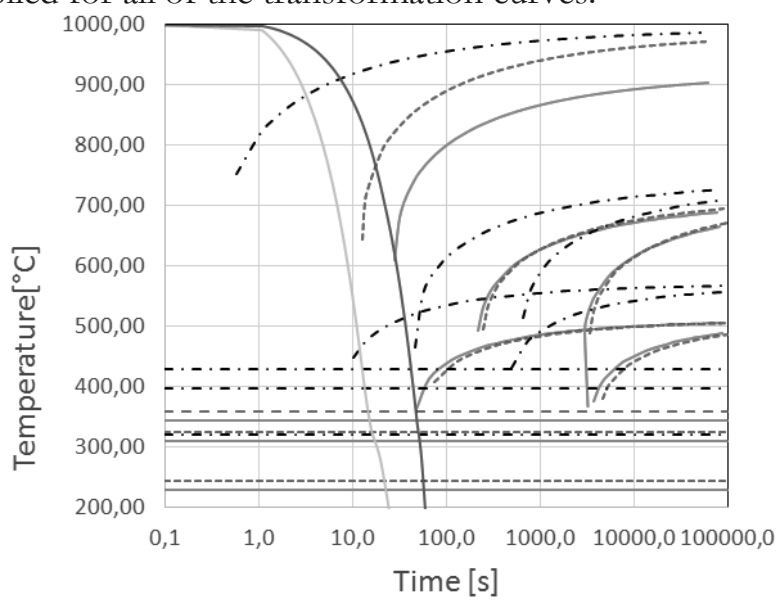

Fig. 1 Summarizing CCT diagram (1.5 Al3Mn - full lines - green, 2 Al3Mn - dashed lines - red, 1.5Al1.5Mn - dot and dashed lines - black) with real dilatometric cooling curves $\left(50^{\circ} \mathrm{C} / \mathrm{s}, 14^{\circ} \mathrm{C} / \mathrm{s}\right)$

Tab. 2 Software-calculated transformation temperatures for three experimental steels

\begin{tabular}{cccccc}
\hline $\begin{array}{c}\mathbf{T} \\
{\left[{ }^{\circ} \mathbf{C}\right]}\end{array}$ & Ac1 & Ac3 & Ms & M50 & M90 \\
\hline $1.5 \mathrm{Al}-3 \mathrm{Mn}$ & 709 & 920 & 344 & 309 & 228 \\
$2 \mathrm{Al}-3 \mathrm{Mn}$ & 716 & 986 & 358 & 324 & 244 \\
$1.5 \mathrm{Al}-1.5 \mathrm{Mn}$ & 740 & 992 & 429 & 396 & 321
\end{tabular}

\subsection{Ac1 and Ac3 experimental determination}

Fig. 2 demonstrates determination of the Ac1 and Ac3 transformation temperatures as deviations from the tangents to the elongation data which represent a fully untransformed resp. fully austenitic state of the microstructure.

The resulting $A_{c 1}$ and $A_{c 3}$ values (Tab. 3) correspond with the software calculated results, i.e. increased $\mathrm{Mn} / \mathrm{Al}$ ratio is responsible for decreasing the transformation temperatures. Another difference between the materials can be found in the amount of expansion during the transformation period between $\mathrm{A}_{\mathrm{c} 1}$ and $\mathrm{A}_{\mathrm{c} 3}$. Material $2 \mathrm{Al}-3 \mathrm{Mn}$ underwent the most significant length change $(+9 \mu \mathrm{m})$, since the thermal

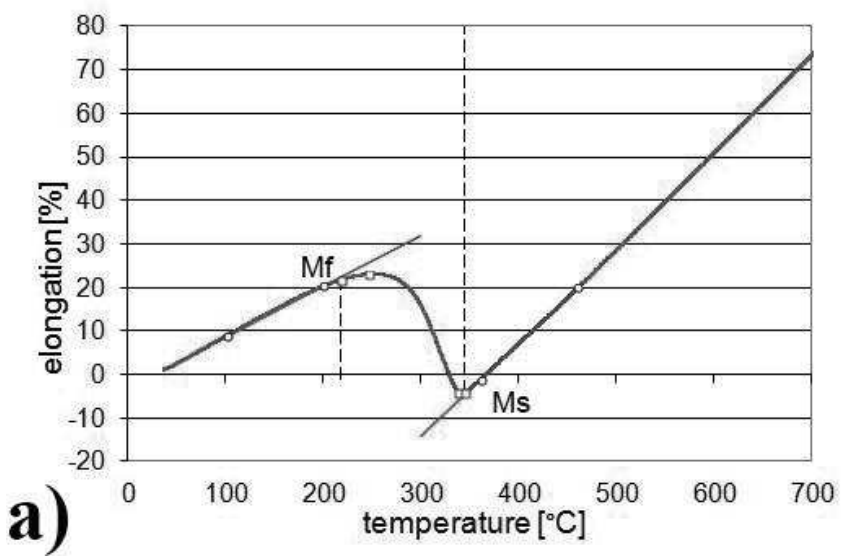

expansion prevailed over the phase transformation induced shrinkage more distinctively. Material 1.5Al $1.5 \mathrm{Mn}$ exhibits smaller elongation $(+2 \mu \mathrm{m})$, whereas the length of $1.5 \mathrm{Al}-3 \mathrm{Mn}$ steel sample was reduced by $3 \mu \mathrm{m}$ on average during the transformation.

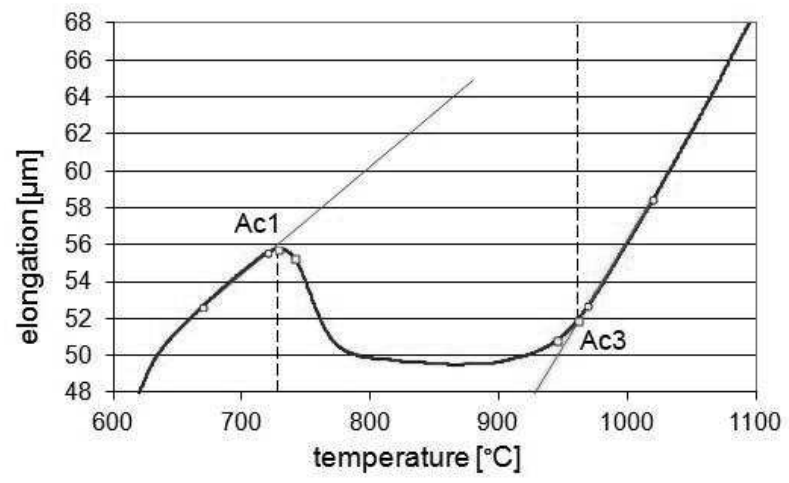

Fig. 2 Dilatometric data, measurement of $A_{c 1}$ and $A_{c 3}$ transformation temperatures, material $1.5 \mathrm{Al}-3 \mathrm{Mn}$

Tab. 3 Transformation temperatures Ac1 and Ac3 with corresponding elongations, average values from two dilatometric measurements.

\begin{tabular}{ccccc}
\hline & \multicolumn{2}{c}{ Ac1 } & \multicolumn{2}{c}{ Ac3 } \\
\hline & $\mathbf{T}\left(^{\circ}\right.$ & $\mathbf{\Delta} \mathbf{l}(\boldsymbol{\mu}$ & $\mathbf{T}$ & $\boldsymbol{\Delta l}(\boldsymbol{\mu}$ \\
& $\mathbf{C})$ & $\mathbf{m})$ & $\left.{ }^{\circ} \mathbf{C}\right)$ & $\mathbf{m})$ \\
\hline $1.5 \mathrm{Al}-3 \mathrm{Mn}$ & 728 & 58.15 & 960 & 55.65 \\
$2 \mathrm{Al}-3 \mathrm{Mn}$ & 739 & 58.0 & 1025 & 67.0 \\
$1.5 \mathrm{Al}-$ & 760 & 48.1 & 1028 & 50.2 \\
$1.5 \mathrm{Mn}$ & & & &
\end{tabular}

\subsection{Ms and Mf experimental determination}

Figure 3. shows the dilatometric determination of martensite and bainite formation temperatures with identical cooling rates of $14{ }^{\circ} \mathrm{C} / \mathrm{min}$. Consistently with calculated CCT diagrams, only martensitic transformation was detected in $1.5 \mathrm{Al}-3 \mathrm{Mn}$ and $2 \mathrm{Al}-3 \mathrm{Mn}$ steels for this cooling rate, while $1.5 \mathrm{Al}-1.5 \mathrm{Mn}$ steel reached the bainitic region at $540{ }^{\circ} \mathrm{C}$ (Figure 4, Table 3).

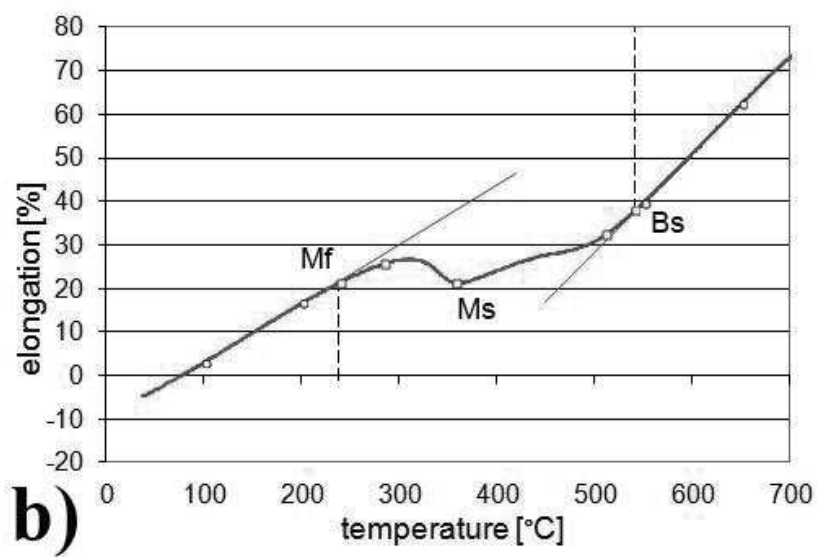

Fig. 3 Dilatometric data, cooling rate $14^{\circ} \mathrm{C} / \mathrm{s}$, a) material $1.5 \mathrm{Al}-3 \mathrm{Mn}$, b) material $1.5 \mathrm{Al}-1.5 \mathrm{Mn}$ 
The lowest martensite formation temperature (319 ${ }^{\circ} \mathrm{C}$ ) was measured for $2 \mathrm{Al}-3 \mathrm{Mn}$ steel (Table 3.), which doesn't correspond with the calculated model (Fig. 1, Tab. 2). On the other hand, both methods confirmed $1.5 \mathrm{Al}-1.5 \mathrm{Mn}$ steel as the material with the highest $\mathrm{M}_{\mathrm{s}}$ temperature.

Tab. 4 Cooling rate dependent transformation temperatures $M s, M f\left({ }^{\circ} \mathrm{C}\right)$ acquired with dilatometric measurement $\left({ }^{*}\right.$ bainitestart)

\begin{tabular}{ccccc}
\hline & \multicolumn{2}{c}{$\mathbf{1 4}{ }^{\circ} \mathbf{C} / \mathbf{s}$} & \multicolumn{2}{c}{$\mathbf{5 0}{ }^{\circ} \mathbf{C} / \mathbf{s}$} \\
\hline & $\mathbf{M}_{\mathbf{s}}$ & $\mathbf{M}_{\mathbf{f}}$ & $\mathbf{M}_{\mathbf{s}}$ & $\mathbf{M}_{\mathbf{f}}$ \\
\hline $1.5 \mathrm{Al}-3 \mathrm{Mn}$ & 344 & 216 & 338 & 212 \\
$2 \mathrm{Al}-3 \mathrm{Mn}$ & 336 & 198 & 319 & 192 \\
$1.5 \mathrm{Al}-1.5 \mathrm{Mn}$ & $357\left(540^{*}\right)$ & 238 & 378 & 228
\end{tabular}

Tab. 5 Length changes of the sample at transformation temperatures $M s, M f$ or bainite-start (*) with different cooling rates.

$$
14^{\circ} \mathrm{C} / \mathrm{s} \quad 50^{\circ} \mathrm{C} / \mathrm{s}
$$

\begin{tabular}{ccccc}
\hline & $\boldsymbol{\Delta} \mathbf{l}_{\mathbf{M s}}(\mu \mathrm{m})$ & $\begin{array}{c}\Delta \mathbf{l}_{\mathbf{M f}} \\
(\mu \mathbf{m})\end{array}$ & $\boldsymbol{\Delta} \mathbf{l}_{\mathbf{M s}}(\boldsymbol{\mu m})$ & $\begin{array}{c}\boldsymbol{\Delta} \mathbf{l}_{\mathbf{M f}} \\
(\boldsymbol{\mu} \mathbf{m})\end{array}$ \\
\hline $1.5 \mathrm{Al}-3 \mathrm{Mn}$ & -4.1 & 21.7 & -1.9 & 20.8 \\
$2 \mathrm{Al}-3 \mathrm{Mn}$ & $-5.7^{*}$ & 16.7 & -6.7 & 15.8 \\
$1.5 \mathrm{Al}-1.5 \mathrm{Mn} 21.3\left(37.9^{*}\right)$ & 21.3 & 4.7 & 19.2
\end{tabular}

At cooling rate $50^{\circ} \mathrm{C} / \mathrm{s}$ all three steels exhibit very similar length change during the martensitic transformation (approx. $23 \mu \mathrm{m}$ ), however, the $2 \mathrm{Al}-3 \mathrm{Mn}$ shows

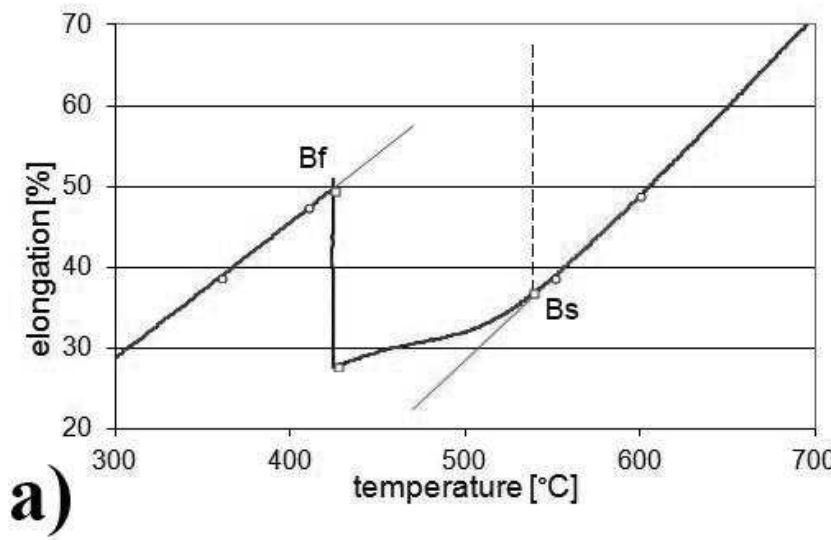

the least deformation at $\mathrm{M}_{\mathrm{f}}$ temperature (Tab. 5) compared to the initial state. Based on this finding, the $2 \mathrm{Al}-3 \mathrm{Mn}$ steel could be considered the least susceptible to deformation induced by phase transformation during rapid cooling.

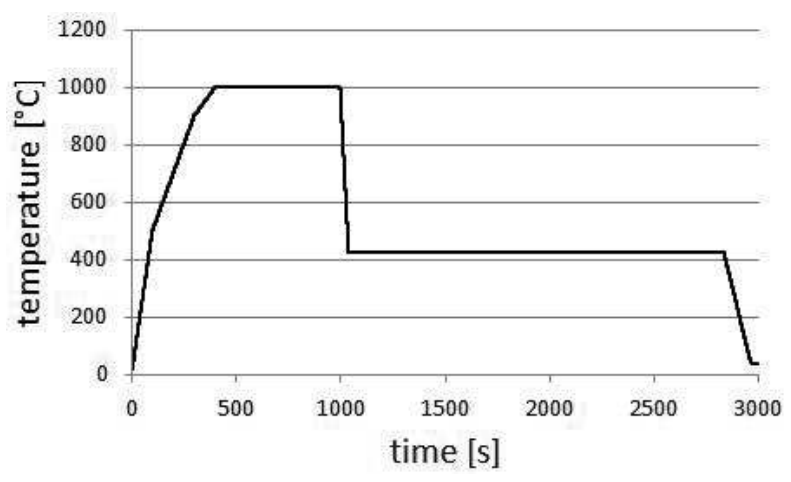

Fig. 5 Heat treatment procedure simulated by dilatometer

The last and the most time consuming dilatometric measurement was performed to simulate a heat treatment procedure with soaking at $1000^{\circ} \mathrm{C}$ and 30 minute hold at the temperature of bainitic transformation (Fig. 5). Figure 6. shows the difference between $1.5 \mathrm{Al}$ $-1.5 \mathrm{Mn}, 1.5 \mathrm{Al}-3 \mathrm{Mn}$. Again, coincidently with computations and previous experiments, $1.5 \mathrm{Al}-1.5 \mathrm{Mn}$ enters the bainitic transformation region at approx. $540{ }^{\circ} \mathrm{C}$, i.e. before the temperature dwell period started. For both $1.5 \mathrm{Al}-3 \mathrm{Mn}$ and $2 \mathrm{Al}-3 \mathrm{Mn}$ the bainitic transformation started during the 30 minute hold at $425^{\circ} \mathrm{C}$.

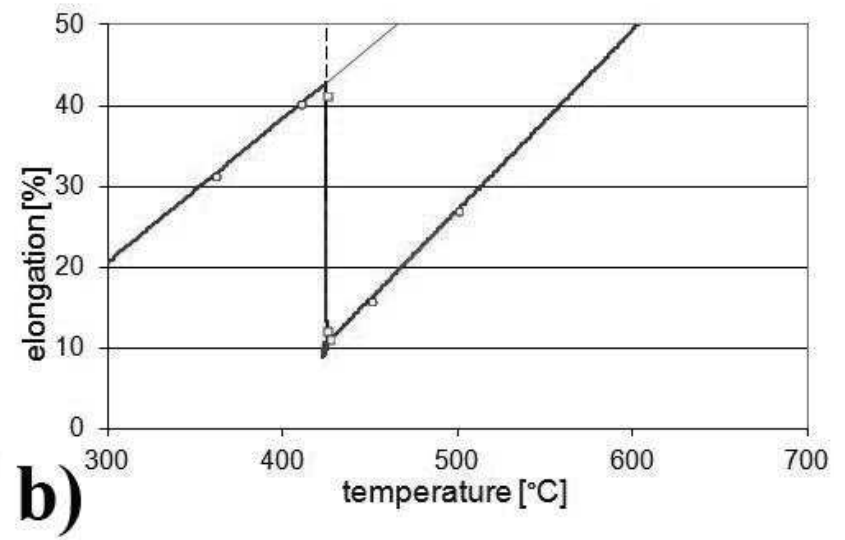

Fig. 6 Dilatometric data - cooling and bold in the bainitic region, a) material 1.5 Al-1.5Mn, b) material 1.5 Al-3Mn steel

The microstructure of $1.5 \mathrm{Al}-3 \mathrm{Mn}$ steel (Fig. $7 \mathrm{a}$ ) obtained by a two-step annealing consisted of the bainitic-martensitic mixture. The bainite had predominantly lath morphology with occasional occurrence of long laths. Martensitic areas were large a numerous suggesting that the hold at $425{ }^{\circ} \mathrm{C}$ was too short to ensure complete bainitic transformation and large areas of remaining austenite transformed to martensite during the final cooling to room temperature.

The microstructure of 2Al-3Mn steel (Fig. 7b) was still containing the bainitic-martensitic mixture, however, the amount of martensite was lower, than in the case of $1.5 \mathrm{Al}-3 \mathrm{Mn}$ steel and the islands were distinctively finer. Particularly the smaller islands could besides martensite contain also some retained austenite, forming so-called M-A constituent. It could be assumed that bainitic hold was too short also for $2 \mathrm{Al}-$ $3 \mathrm{Mn}$ steel and some austenitic areas were retained during the hold without being properly stabilized against martensitic transformation during the final cooling. The bainitic matrix is made of lath bainite. 

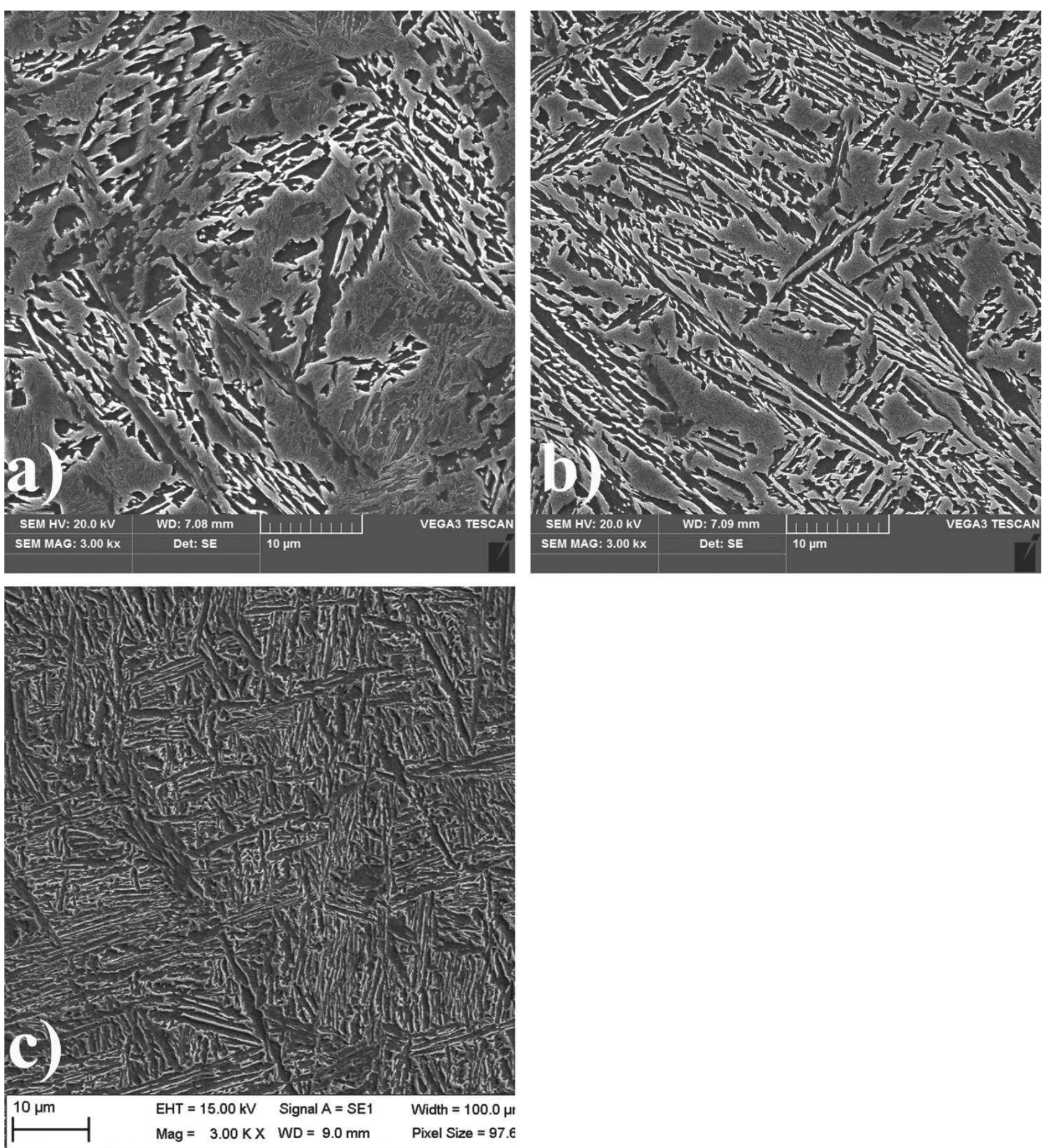

Fig. 7 SEM micrographs after soaking at $1000^{\circ} \mathrm{C}$ and 30 minute hold at $425^{\circ} \mathrm{C}$, a) $1.5 \mathrm{Al}-3 \mathrm{Mn}$ b) $2 \mathrm{Al}-3 \mathrm{Mn}$ c) $1.5 \mathrm{Al}-1.5 \mathrm{Mn}$

The fully bainitic microstructure was obtained for 1.5Al-1.5Mn steel (Fig. 7c). As was already seen from dilatometric curves, bainitic transformation in this steel started already during the cooling from a soaking temperature, at the temperature of $540{ }^{\circ} \mathrm{C}$. The transformation than continued during the hold at $425^{\circ} \mathrm{C}$, which was sufficiently long to result in the bainitic microstructure. The bainite is predominantly of the lath type, however there are also areas of granular bainite in the microstructure. Few individual very long laths, mainly of bainitic ferrite, could be observed, as well as low numbers of fine islands of $\mathrm{M}$-A constituent. These islands typically had the sizes of several micrometers.

\section{Conclusions}

The experiment has proved the computationbased expectations concerning the beneficial effect of manganese and aluminium as the main alloying elements of the experimental steels. Based on the dilatometric measurements accompanied by microstructural analysis, it can be concluded that the manganese / alu- 
minium ratio can be considered an indicator determining the transformation behaviour. From the industrial point of view, the most important consequence of increasing the $\mathrm{Mn} / \mathrm{Al}$ ratio is postponing the isothermal bainitic transformation. The lowest martensite start temperature and thus the most effective austenite stabilisation, was achieved with the ratio $\mathrm{Mn} / \mathrm{Al}$. The dilatometric measurement also recorded different volume changes related to varying proportions of different constituents emerging in the microstructure. The $2 \mathrm{Al}-3 \mathrm{Mn}$ steel showed the least total elongation martensitic/bainitic transformation, which can be beneficial in terms of processability with thermomechanical treatment.

\section{Acknowledgement}

The present contribution has been prepared with the support of the student grant competition of University of West Bohemia in Pilsen, SGS 2018048 Design of heat and thermo-mechanical treatment of high strength steels of the third generation. The project is subsidised from specific resources of the state budget for research and development.

\section{References}

[1] CAI, MING HUI, et al. (2017). Enhanced tensile properties of a reversion annealed $6.5 \mathrm{Mn}$ TRIP alloy via tailoring initial microstructure and cold rolling reduction. In: Journal of Materilal Science and Technology. No. 34, pp. 1428-1435.

[2] KUCEROVA, L. and BYSTRIANSKY, M. (2017). Comparison of thermo-mechanical treatment of C-Mn-Si-Al-Nb Trip steels. In: Procedia Engineering. pp. 1856-1861.

[3] IGOR BARÉNYI, JOZEF MAJERÍK, JÁN BEZECNÝ, MICHAL KRBAŤA, JOSEF SEDLÁK, ALEŠ JAROŠ. (2019). Material and Technological Aspects while Processing of Selected Ultra High Strength Steel. In: Manufacturing Technology, Vol. 19, No. 2, pp. 184-189 | DOI: $\quad 10.21062 /$ ujep/267.2019/a/12132489/MT/19/2/184

[4] KUCEROVA, L., OPATOVA, K. and KANA, K. (2017) High Versatility of Niobium alloyed AHSS. In: Archives of Meatlurgy and Materials. Vol. 62, No.3, pp. 1485-1491.

[5] SUH, DOONG-WOO, KIM, SUNG-JOON. (2016) Medium Mn transformation-induced plasticity steels: Recent progress. In: Scripta $M a$ terialia. No.126, pp. 63-67.

[6] KUCEROVA, L., et al. (2018). Effect of aluminum and manganese Contents on the Microstructure Development of Forged and Annealed TRIP Steel. In: Manufacturing Techno$\log y$. Vol. 18, No. 4, pp. 605-610.

[7] LIU, MINGXIANG, et al., et al. (2019). High ductility of spray formed low density TRIP steel with the improvement of $\delta$-ferrite matrix. In: Materials Characterization. No.19, pp. 1-18.

[8] MONIKA ORAVCOVÁ, PETR PALEČEK, MÁRIUSZ KRÓL (2016), Dilatometric Measurements of Austenitic Stainless Steel as a Function of Temperature. In: Manufacturing Technology, Vol. 16, No. 1, pp. 230-234

[9] MORAWIEC M., GRAJCAR, A., ZALECKI, W., GARCIA-MATEO, C., OPIELA, M., Dilatometric Study of Phase Transformations in 5 Mn Steel Subjected to Different Heat Treatments. In: Materials, Vol. 13, No. 4.

[10] JANEKOVÁ, D., DUBEC, A., BURGET M., PEŠLOVÁ, F. (2018), The Heat Treatment Impact on Material Properties of $34 \mathrm{CrNiMo6}$ Steel, In: Manufacturing Technology, Vol. 18 No 6, pp. 912-916 | DOI: 10.21062/ujep/200.2018/a/1213-

2489/MT/18/6/912

[11] KUCEROVA, L. (2017). The Effect of TwoStep Heat Treatment Paremeters on Microstructure and Mechanical Properties of 42MnSi Steel. In: Metals. Vol. 7, No. 12.

[12] KALINCOVÁ, D., ŤAVODOVÁ, M., KAŠTAN, R., Inovation Heat Treatment of Coining Dies - Analysis of the Microstructural Parameters Tool Steels. In: Manufacturing Technology, Vol. 16, No. 5, pp. 939-946

[13] VOREL, I., JENÍČEK, Š., KÁNA, J., IBRAHIM, K., KOTĚŠOVEC, V. Use of Optical and Electron Microscopy in Evaluating Optimization by Material-Technological Modelling of Manufacturing Processes Involving Cooling of Forgings, In: Manufacturing Technology, Vol. 16, No. 6, pp. 1383-1387

[14] KUCEROVA, L., JIRKOVA, H., MASEK, B. (2015). Continuous cooling of CMnSi TRIP steel. In: Materials Today: Proceedings. pp. 677680. 